ON THE NECESSITY OF CULTIVATING WATER BACTERIA IN AN ATMOSPHERE SATURATED WITH MOISTURE

BY GEORGE C. WHIPPLE, S.B.

Reprinted from Trchnology Quarterly, Volume XII, No. 4, December, 1899 
M I L L E R's
White Cloth Flap Binders, HAROLD E. MILLER

540-542-544-546 B'way, Albany, N. Y. SEND FOR PRICHS. 


\section{ON THE NECESSITY OF CULTIVATING WATER BAC- TERIA IN AN ATMOSPHERE SATURATED WITH MOISTURE.}

By GEORGE C. WHIPPLE, S. B.

ACCORDING to present practice the number of bacteria in a sample of water is found by mixing a certain quantity of the water with a certain quantity of sterilized nutrient gelatin and allowing the mixture to solidify in a Petri dish. After a longer or shorter period of incubation at a temperature at or about $20^{\circ} \mathrm{C}$., the colonies that have developed upon the gelatin are counted, and from this count the number of bacteria present in the water is determined. Although this method is almost universally used, and although the results obtained are sometimes of the greatest moment, there is such a lack of uniformity in the details of the process as ordinarily conducted, that the determinations of different observers are seldom comparable unless the methods of procedure are fully described. A standard method of procedure is urgently needed, but cannot be secured until the various factors that influence the result have been analyzed and their magnitude determined. In the course of a series of experiments conducted with this object in view, it was observed that the amount of moisture in the atmosphere of the incubator exercised an important influence upon the number of bacteria that developed. The results of these observations are summarized in this paper.

Before the use of the Petri dish it was customary to pour the mixed gelatin and water upon a cold glass plate, where it was allowed to spread out and harden. The plate was then covered with a bell-jar and put in the incubator. In order to prevent the gelatin from drying, moist filter paper was put at the bottom of the bell-jar. Thus the bacteria developed in a moist atmosphere. With the advent of the Petri dish the matter of moisture seems to have been lost sight of. This dish was provided with a tight fitting cover, and this was supposed to prevent evaporation from the gelatin. It is a fact, however, that the Petri dishes now on the market are not tight, and that often the covers 
fit the plates very badly. Furthermore, in laboratories where many dishes are in daily use, it is a common thing for dishes and covers to be mismated, and often there is no attempt to mate them. The result is that an appreciable evaporation from the gelatin does take place, and that the amount of evaporation varies with different plates and with different atmospheric conditions.

The effect which this uncontrolled factor exercises upon the development of bacteria is shown by the following experiments. Several series of cultures were submitted to varying conditions of moisture, with other conditions remaining constant. The plates were incubated in a moist chamber, in a closed chamber without moisture, in the incubator (or the ice chest), and in a desiccator. For the moist chamber a desiccator-jar was used, the sulphuric acid being replaced by water. The closed chamber was a desiccator-jar without sulphuric acid or water. The jars were large enough to hold five plates, and in all cases the figures representing the numbers of bacteria found were obtained from the averages of the five counts. The results are given in the following tables. Table I shows the average number of bacteria that developed upon each set of plates. In Table II these figures are reduced to percentages of the number that developed in the moist chamber.

TABLE I.

\begin{tabular}{|c|c|c|c|c|c|c|c|c|}
\hline \multirow[b]{2}{*}{ Series. } & \multirow[b]{2}{*}{ Date. } & \multirow{2}{*}{ 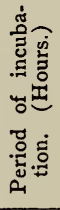 } & \multirow{2}{*}{ 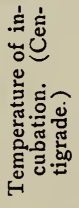 } & \multicolumn{5}{|c|}{ Number of Bactrria Per Cubic Crntimeter. } \\
\hline & & & & $\begin{array}{l}\text { In moist } \\
\text { chamber. }\end{array}$ & In ice chest. & In incubator. & $\begin{array}{l}\text { In closed } \\
\text { chamber. }\end{array}$ & In desiccator. \\
\hline A. & $\begin{array}{c}\text { I899. } \\
\text { July } 7 .\end{array}$ & 96 & $16^{\circ}$ & 583 & 527 & - & - & 465 \\
\hline B. & July 7 . & 96 & $16^{\circ}$ & 507 & 430 & 一 & - & 415 \\
\hline C. & July 7 . & 96 & $16^{\circ}$ & 750 & 683 & - & - & 618 \\
\hline D. & Oct. 9. & 96 & $15^{\circ}$ & 450 & 438 & - & 395 & 342 \\
\hline E. & May 20. & 72 & $18^{\circ}$ & 154 & 一 & 115 & 一 & 111 \\
\hline F. & Oct. 14. & 72 & $20^{\circ}$ & 108 & - & 89 & 90 & 84 \\
\hline G. & Oct. 9. & 48 & $20^{\circ}$ & 423 & - & 413 & 354 & 324 \\
\hline H. & Oct. 17. & 72 & $20^{\circ}$ & 61 & - & 59 & - & 51 \\
\hline
\end{tabular}


TABLE II.

\begin{tabular}{|c|c|c|c|c|c|c|c|c|}
\hline \multirow[b]{2}{*}{ Series. } & \multirow[b]{2}{*}{ Date. } & \multirow{2}{*}{ 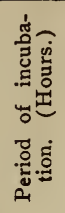 } & \multirow{2}{*}{ 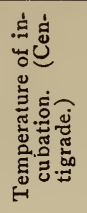 } & \multicolumn{5}{|c|}{$\begin{array}{l}\text { Per Cent. Which Each NUmber was of the Number } \\
\text { Found in the Motst Chamber. }\end{array}$} \\
\hline & & & & $\begin{array}{l}\text { In moist } \\
\text { chamber. }\end{array}$ & In ice chest. & In incubator. & $\begin{array}{l}\text { In closed } \\
\text { chamber. }\end{array}$ & In desiccator. \\
\hline A. & $\begin{array}{c}\text { 1899. } \\
\text { July } 7 .\end{array}$ & 96 & $16^{\circ}$ & 100 & 90 & - & - & 79 \\
\hline B. & July 7 . & 96 & $16^{\circ}$ & 100 & 85 & - & - & 82 \\
\hline C. & July 7 . & 96 & $16^{\circ}$ & 100 & 91 & - & - & 82 \\
\hline D. & Oct. 9. & 96 & $15^{\circ}$ & 100 & 98 & - & 88 & 79 \\
\hline$\dot{\mathrm{E}}$. & May 20. & 72 & $18^{\circ}$ & 100 & - & 75 & - & 73 \\
\hline F. & Oct. 14. & 72 & $20^{\circ}$ & 100 & - & 82 & 83 & 77 \\
\hline G. & Oct. 9. & 48 & $20^{\circ}$ & 100 & - & 98 & 83 & 77 \\
\hline $\mathrm{H}$. & Oct. 17. & 72 & $20^{\circ}$ & 100 & - & 97 & - & 83 \\
\hline Average. & ...... & .. & .. & 100 & 91 & 88 & 85 & 78 \\
\hline
\end{tabular}

From these tables it will be seen that the largest numbers of bacteria were always obtained from the plates that developed in the moist chamber, and that the smallest numbers were always obtained from the plates that were kept in the desiccator. If the number that developed in the moist atmosphere be assumed to represent the maximum number obtainable by the method, it follows that only 78 per cent. of the bacteria developed in the desiccator, that 85 per cent. developed in the closed chamber, and that the numbers that developed in the ordinary incubator and in the ice chest varied from 75 per cent. to 98 per cent. There was a striking uniformity in the percentages which the numbers in the desiccator were of the numbers in the moist chamber and this was due, no doubt, to the constant atmospheric conditions in the two jars. In the closed chamber also the percentages were quite constant. In the ice chest and in the incubator the percentages were more variable. The atmosphere of the ice chest was ordinarily more moist than that of the incubator, but was seldom saturated on account of ventilation. The amount of moisture in the air of the incubator was generally greater than that of the atmosphere of the laboratory, and varied more or less with the ventilation, the number of plates kept in the incubator, etc. In Series $E$ the relative humidity 
of the atmosphere in the incubator was estimated at about 60 per cent. In Series $\mathrm{F}$ the humidity was determined by hourly readings of a psychrometer and was found to vary between 65 per cent. and 80 per cent., the average being 75 per cent. In Series $G$ the atmosphere of the incubator was kept moist by means of jars of water, and the average humidity was 95 per cent. In Series $H$ the humidity was similarly kept at 98 per cent. of saturation. The relation between the humidity and the development of bacteria is shown by the following comparison :

\begin{tabular}{c|c|c}
\hline Series. & $\begin{array}{c}\text { Relative Humidity of the Atmosphere } \\
\text { of the Incubator in per cent. of } \\
\text { Saturation. }\end{array}$ & $\begin{array}{c}\text { Per cent. which the Number of Bacte- } \\
\text { ria that Developed in the Incubator } \\
\text { was of the Number that Devel- } \\
\text { oped in the Moist Chamber. }\end{array}$ \\
\hline E. & 60 (estimated.) & 75 \\
F. & 75 & 82 \\
G. & 95 & 98 \\
H. & 98 & 97 \\
\hline
\end{tabular}

The amount of evaporation from gelatin under the conditions described above was determined by weighing the dishes with their contents before and after incubation. It was found that in a saturated atmosphere the evaporation was inappreciable; in the closed chamber it was from I to 2 per cent. of the weight of the mixed water and gelatin during 72 hours; in the ice chest it was about 3 per cent.; in the incubator it was from 3 per cent. to 5 per cent.; and in the desiccator it was from ro per cent. to I 5 per cent. The amount of evaporation varied greatly with different plates submitted to the same conditions.

This loss of water by evaporation is sufficient to cause important changes in the composition of the culture media during incubation, and this may be sufficient to affect the development of the bacteria, as these organisms are very susceptible to slight changes in environment. But the chief reason why increased evaporation is accompanied by a decrease in the percentage of bacteria that develop seems to be connected with the supply of oxygen. By successive weighing of the same plates it was found that the rate of evaporation was not constant, but decreased rapidly. For example, during the first hour 
of incubation the evaporation from a series of plates proceeded at the rate of .068 gram per hour; after 18 hours the rate of evaporation was .03I gram per hour; after 42 hours it was .OI 2 gram per hour, and after 96 hours it was .002 gram per hour. This retardation of the rate of evaporation appears to be due to a thickening of the gelatin at the surface. If such is the case, the thickened gelatin at the surface might materially reduce the supply of oxygen of the submerged bacteria and prevent the development of the less vigorous aërobic forms. Indeed, it was observed that the plates in the desiccator and in the moist chamber differed more in the number of submerged colonies than in the number of surface colonies.

These facts suggested the possibility that the Petri dish itself might serve to prevent the bacteria from getting a sufficient supply of oxygen. The experiment was made, therefore, of cultivating the bacteria in a Petri dish with the ordinary cover replaced by a ground glass top that made an absolutely air tight joint. A series of five cultivations made in this way gave the number of bacteria in a certain sample as 3I 7 per cc., while a series of cultivations of the same water made in the usual manner gave $4 \mathrm{I} 3$ per cc. In the hermetically sealed dish, therefore, only 77 per cent of the bacteria developed. The air of these dishes was then collected over mercury, and the amount of oxygen determined by absorption with pyrogallic acid. It was found that the air of the ordinary dishes contained approximately I 5 per cent. of oxygen, while the air of the sealed dishes contained only 5 per cent. In other words, three-quarters of the original supply of oxygen in the sealed dishes had been used up by the bacteria during 72 hours, while one-quarter of the original supply had been used up in the ordinary dishes. It was found also that the air in the sealed dishes contained 5 per cent. of $\mathrm{CO}_{2}$, while the air in the ordinary dishes contained but 2 per cent.

As a matter of interest a series of cultures was made in a jar filled with oxygen, and compared with cultures of the same water made in the incubator. It was found that the average number of colonies that developed in the oxygen was I 54 per cc., while in the incubator it was 137. The growth in oxygen also took place at a much more rapid rate.

Finally, one important fact was noted in connection with the cultures made in the jars that illustrates the important effect of oxygen. In all the jars the five Petri dishes were piled one on top of the other, 
and it was found that almost invariably the plate highest in the jar gave the largest count, and that the lowest plate gave the smallest count. This was particularly striking in the case of the jar filled with oxygen, where the upper plate contained I98 colonies per cc., while the lower plate contained I 38 . These differences between the upper and lower plates of the jars were greater than the differences observed between plates kept in the incubator. Liquefaction proceeded much more rapidly in the upper plates of the jars. These phenomena seemed to be due to an accumulation of carbon dioxide at the bottom of the jars, where either by its own properties or by exclusion of oxygen, it retarded the growth of the bacteria.

These facts tended to show that the supply of oxygen has a marked effect upon the growth of water bacteria on the gelatin plate, and that whatever tends to reduce the supply of oxygen, whether it be evaporation or an air-tight Petri dish or lack of sufficient ventilation, will tend also to reduce the number of bacteria. The practical inference from this is that in order to obtain the greatest possible development of water bacteria on the gelatin plate, a ventilated dish should be used, and the cultures should be incubated in an atmosphere saturated with moisture.

It has been found that satisfactory ventilation of the Petri dishes may be obtained by grinding several small notches in the edge of the lower plate. If greater ventilation is required, it may be obtained by extending the sides of the lower plate upwards at four points on the circumference so as to form pillars for supporting the cover, thereby allowing a complete circulation of air. It has been found that the bacteria counts obtained by using these ventilated dishes in an atmosphere saturated with moisture, compare closely with those obtained in open dishes protected from contamination and incubated in a saturated atmosphere, the results of one series of comparisons giving 97 and 95 bacteria per cc. respectively, by the two methods. Experiments have shown that there is no danger of these ventilated plates becoming contaminated from the air.

The cultivation of water bacteria in the moist atmosphere has the further advantage that the growths come to maturity in a shorter time. Liquefaction takes place earlier, but the growth of the deep-seated colonies seems to proceed at a still more rapid rate. A greater proportion of the plates are liquefied after 72 hours' growth, but on the other hand, the percentage increase between the 48-hour count and the 72 -hour count is much reduced. 
Incubators used for the cultivation of water bacteria should be well ventilated, and their atmosphere should be kept at or near the point of saturation. They should be provided with wet and dry bulb thermometers, and the relative humidity should not be allowed to fall below 95 per cent. Experience has shown that an atmosphere practically saturated with moisture may be easily maintained.

Mt. Prospect laboratory,

Flatbush avenue and Eastern Parkway,

Brooklyn, N. Y. 


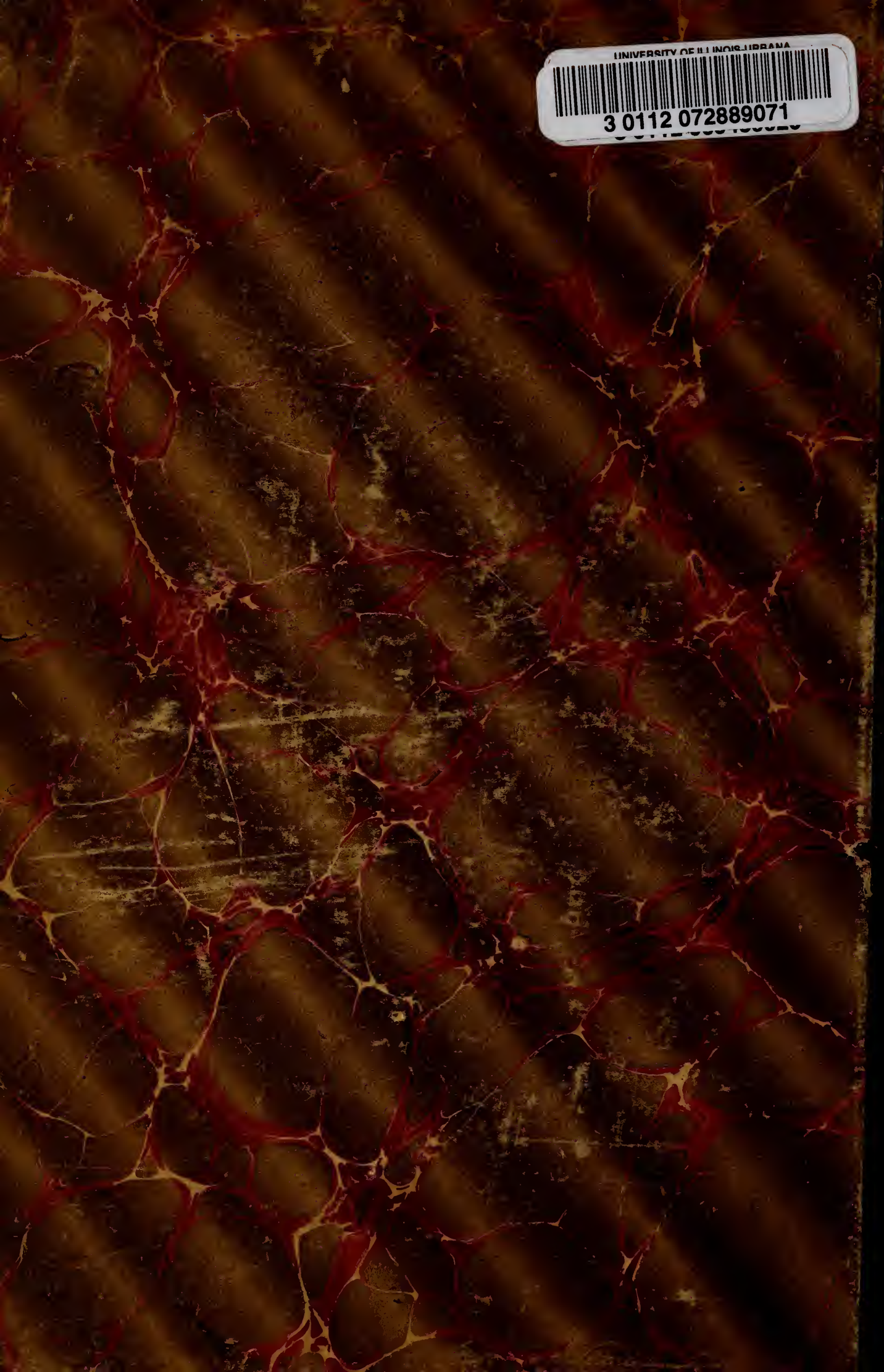